\title{
Online Compensation of Parameter Variation Effects for Robust Interior PM Synchronous Motor Drives
}

\author{
Rajendra L. Shrestha* and Jul-Ki Seok ${ }^{\dagger}$ \\ * Chilime HydroPower Company, Rasuwa, Nepal \\ ${ }^{\dagger}$ Power Conversion Lab., Dept. of Electrical Eng., Yeungnam University, Gyeongsan, Korea
}

\begin{abstract}
This paper presents an online voltage disturbance estimator to achieve precise torque control of IPMSMs over a high speed operating region. The proposed design has a type of state-filter based on a Luenburger-style closed loop stator current vector observer. Utilizing the frequency response plot (FRF) approach, the estimation accuracy and the parameter sensitivities are analyzed. Accurate torque control and improved efficiency are provided with the decoupling of the effect of the parameter variations. The feasibility of the presented idea is verified by laboratory experiments.
\end{abstract}

Key Words: Accurate torque control, Interior permanent magnet synchronous motor, Parameter variations, Voltage disturbance estimator

\section{INTRODUCTION}

Interior permanent-magnet synchronous motors (IPMSMs) have received a great deal of attention in the field of automotive traction applications due to their unique features, such as high efficiency, high power density, and a wide constant power speed range [1]. The drive systems in these applications require strict torque regulation specifications that are less than $\pm 5 \%$ of the rated value in the overall operating range [2].

The Maximum Torque Per Ampere (MTPA) operation, which computes the theoretical current command vector to minimize the copper losses, is the most widely used approach to achieve the desired air gap torque of IPMSMs [3], [4]. Current control is the most widely used approach to manipulate the air gap torque of IPMSMs. It should be noted, that when using current control, both the air gap torque and the flux linkage are open loop variables. Thus, accurate torque control is often precluded because of model errors due to parameter variations. In the constant power region, the magnetic saturation effect as well as temperature variations significantly influence the accuracy of the torque control because the flux varies as the rotor speed increases.

One common remedy for curing this problem involves lookup tables based on steady-state measurements of the motor voltages, currents, and torque [5]-[7]. Multi-dimensional or numerous look-up tables are required to cover the whole MTPA space, including the high saturation and PM flux/stator resistance variations. This is computationally intensive due to

\footnotetext{
Manuscript received Jan. 19, 2011; revised Jun. 17, 2011

Recommended for publication by Associate Editor Kyeong-Hwa Kim.

$\dagger$ Corresponding Author: doljk@ynu.ac.kr

Tel: +82-53-810-2484, Fax: +82-53-810-4767, Yeungnam University

* Chilime HydroPower Company, Nepal
}

the non-linearity caused by magnetic saturation and temperature variations. Furthermore, a cross saturation effect is both intensive and very difficult to estimate in offline methods.

This paper presents an online voltage disturbance estimator design to achieve the precise torque control of IPMSMs over a flux weakening operating region. The proposed design has a type of state-filter based on a Luenburger-style closed loop stator current observer. Utilizing the frequency response function (FRF) approach, the estimation accuracy and the parameter sensitivities are analyzed. With the proposed design, accurate torque control and improved efficiency are provided with the decoupling of the effect of the parameter variations.

\section{IPMSM MODEL IN THE RotOR REFERENCE FRAME}

A model of the IPMSM in the rotor reference frame is applied to design the voltage disturbance estimator. The $\mathrm{d}-\mathrm{q}$ axis voltage equation of the IPM machine in the synchronous reference frame is given by:

$$
\left[\begin{array}{c}
v_{d s}^{r} \\
v_{q s}^{r}
\end{array}\right]=\left[\begin{array}{cc}
R_{s}+p L_{d} & -\omega_{r} L_{q} \\
\omega_{r} L_{d} & R_{s}+p L_{q}
\end{array}\right]\left[\begin{array}{l}
i_{d s}^{r} \\
i_{q s}^{r}
\end{array}\right]+\left[\begin{array}{c}
0 \\
\omega_{r} \lambda_{p m}
\end{array}\right]
$$

where: $R_{s}:$ stator resistance $[\Omega]$

$v_{d s}^{r}, v_{q s}^{r}: \mathrm{d}$ and q axes stator voltage in rotor reference frame $[\mathrm{V}]$

$i_{d s}^{r}, i_{q s}^{r}: \mathrm{d}$ and $\mathrm{q}$ axes stator current in rotor reference frame $[\mathrm{A}]$

$L_{d}, L_{q}: \mathrm{d}$ and $\mathrm{q}$ axes total stator inductances $[\mathrm{H}]$

$\lambda_{p m}:$ permanent magnet flux linkage $[\mathrm{Wb}]$

$p:$ differential operator

$\omega_{r}$ : rotor speed.

The well-known electro-magnetic torque equation of an IPMSM in the rotor reference frame is:

$$
T_{e}=\frac{3}{2} \frac{P}{2}\left(\lambda_{d s}^{r} r_{q s}^{r}-\lambda_{q s}^{r} r_{d s}^{r}\right)
$$




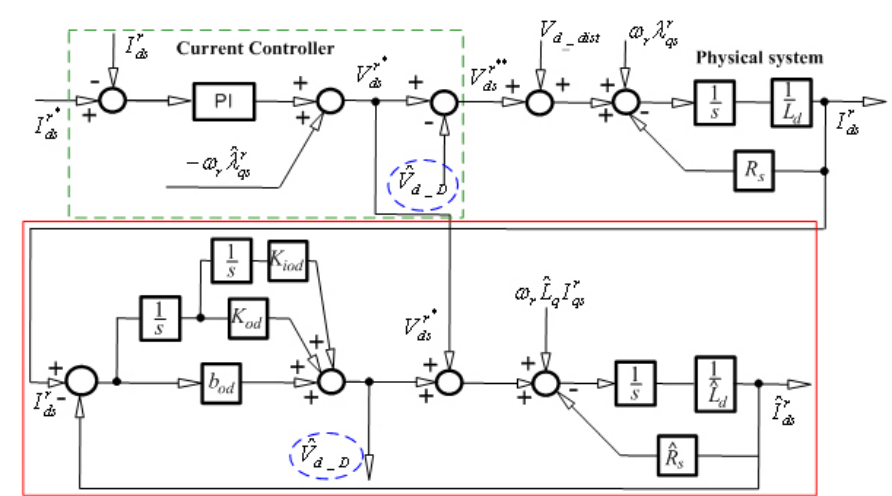

Fig. 1. Block diagram of the proposed d-axis voltage disturbance estimation and compensation approach.

where:

$\lambda_{d s}^{r}=L_{d} i_{d s}^{r}+\lambda_{p m}$ : the d-axis stator flux.

$\lambda_{q s}^{r}=L_{q} i_{q s}^{r}:$ the q-axis stator flux.

$\mathrm{P}$ : the number of poles.

This equation can be rewritten in terms of the machine parameters of the IPMSM as:

$$
T_{e}=\frac{3}{2} \frac{P}{2}\left[\lambda_{p m} i_{q s}^{r}+\left(L_{d}-L_{q}\right) i_{d s}^{r} i_{q s}^{r}\right] .
$$

The first term of (3) corresponds to the PM alignment torque component produced by the interaction between the rotor PM flux linage and the q-axis stator current. The second term defines the reluctance torque due to the magnetic saliency. Since $L_{d}<L_{q}$ and the current vector lies in the third quadrant of the d-q current plane, the reluctance torque component of the above equation is additive. Because of the reluctance torque component, the current vector command for the current control is generally not linearly related to the torque or the flux. The current vector components are computed to theoretically yield the minimum losses while still achieving the desired total torque. Such optimal current vector computations can be implemented with varying degrees of complexity, where the saturation and parameter adaptation can be included to improve the optimization.

In the flux weakening region, such an optimal phase displacement is heavily load-dependent due to the saturation and cross magnetization effect [7]. Therefore, inductance variations are taken into account to achieve precise torque control at high speeds.

\section{Design and Analysis of the Proposed Voltage DISTURBANCE ESTIMATOR}

\section{A. Design and Analysis of the Disturbance Estimator}

Fig. 1 and 2 show a block diagram of a d-q axis voltage disturbance estimation strategy employing a closed-loop Luenberger-style stator current observer [10].

A familiar proportional-integral-integral (PII) type observer controller has been adopted to estimate the voltage disturbance resulting from parameter variations. Because the command voltage vector $V_{d q s}^{r *}$ is fed-forward to the observer, the voltage disturbance error $\hat{V}_{d q_{-} D}$ is estimated at the output of the observer controller. This can estimate and compensate for voltage deviations resulting from disturbances and uncertainties. The

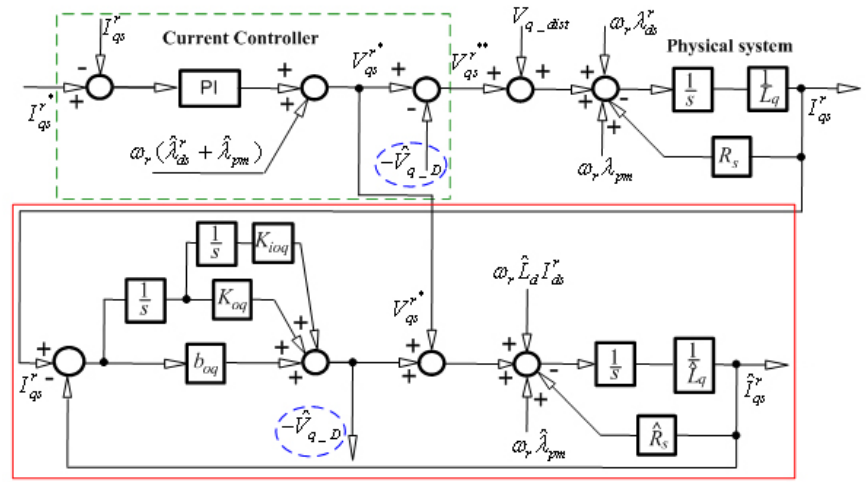

Fig. 2. Block diagram of the proposed q-axis voltage disturbance estimation and compensation approach.

estimated voltage disturbance is compensated by the current controller output in a feed-forward manner.

From the stator voltage equation, the d-axis stator current can be expressed as:

$$
I_{d s}^{r}(s)=\frac{V_{d s}^{r *}+\omega_{r} L_{q} I_{q s}^{r}}{s L_{d}+R_{s}}
$$

From the d-axis disturbance observer, the estimated d-axis current is given by:

$$
\hat{I}_{d s}^{r}(s)=\frac{V_{d s}^{r *}+\hat{V}_{d \_D}+\omega_{r} \hat{L}_{q} I_{q s}^{r}}{s \hat{L}_{d}+\hat{R}_{s}}
$$

where "“" represents the estimated variables. Then, the estimated disturbance voltage is obtained as:

$$
\hat{V}_{d_{-} D}(s)=\left(b_{o d}+\frac{K_{o d}}{s}+\frac{K_{o i d}}{s^{2}}\right)\left(I_{d s}^{r}-\hat{I}_{d s}^{r}\right)
$$

where $b_{o d}, K_{\text {od }}$, and $K_{\text {oid }}$ represent the d-axis state-filter gains.

Substituting (4) and (5) into (6), the transfer function of the d-axis disturbance output can be obtained as:

$$
\begin{aligned}
\hat{V}_{d \_} D(s)= & {\left[\frac{s^{2} b_{o d}+s K_{o d}+K_{o i d}}{s^{3} \hat{L}_{d}+s^{2}\left(b_{o d}+\hat{R}_{s}\right)+s K_{o d}+K_{o i d}}\right] } \\
& {\left[-\frac{\left(V_{d s}^{r *}+\omega_{r} L_{q} I_{q s}^{r}\right)}{s L_{d}+R_{s}}\left(s \Delta \hat{L}_{d}+\Delta \hat{R}_{s}\right)+\omega_{r} \Delta \hat{L}_{q} I_{q s}^{r}\right] }
\end{aligned}
$$

where $\Delta \hat{L}_{d q}$ and $\Delta \hat{R}_{s}$ denote the inductance and the resistance error, respectively. Using (4), (7) can be rewritten as:

$$
\begin{aligned}
\hat{V}_{d_{-} D}(s)= & {\left[\frac{s^{2} b_{o d}+s K_{o d}+K_{o i d}}{s^{3} \hat{L}_{d}+s^{2}\left(b_{o d}+\hat{R}_{s}\right)+s K_{o d}+K_{o i d}}\right] } \\
& {\left[-\left(s \Delta \hat{L}_{d} I_{d s}^{r}+\Delta \hat{R}_{s} I_{d s}^{r}\right)+\omega_{r} \Delta \hat{L}_{q} I_{q s}^{r}\right] . } \\
= & G_{d}(s) V_{d \_d i s t}(s)
\end{aligned}
$$

As can be seen in (8), the state-filter for the estimation of $\hat{V}_{d_{-} D}$ has an inherent phase lagging property and a speed-dependent voltage, including the effect of $\Delta \hat{L}_{q}$, which dominates at high frequencies in the estimation model. Thus, the derivative term $s \Delta \hat{L}_{d} I_{d s}^{r}$ and the resistance drop can be neglected at high frequencies. 
Similarly, for the q-axis disturbance observer, the transfer function is as follows:

$$
\begin{aligned}
\hat{V}_{q_{-} D}(s)= & {\left[\frac{s^{2} b_{o q}+s K_{o q}+K_{o i q}}{s^{3} \hat{L}_{q}+s^{2}\left(b_{o q}+\hat{R}_{s}\right)+s K_{o q}+K_{o i q}}\right] } \\
& {\left[\left(s \Delta \hat{L}_{q} I_{q s}^{r}+\Delta \hat{R}_{s} I_{q s}^{r}\right)+\omega_{r}\left(\Delta \hat{L}_{q} I_{q s}^{r}+\Delta \hat{\lambda}_{p m}\right)\right] } \\
= & G_{q}(s) V_{q_{-} d i s t}(s)
\end{aligned}
$$

where $b_{o q}, K_{o q}$, and $K_{o i q}$ represent the q-axis state-filter gains and $\Delta \hat{\lambda}_{p m}$ indicates the PM flux linkage error. Equation (8) and (9) clearly state that $\hat{V}_{d q_{-} D}$ can be a direct indicator of model errors due to magnetic saturation and thermal conditions.

From $G_{d}(s)$ and $G_{q}(s)$, the estimation accuracy is directly influenced by the errors in $\hat{L}_{d q}$ and $\hat{R}_{s}$. To investigate the parameter sensitivity of the proposed estimator, the frequency response function (FRF), calculated from (8) and (9), is plotted for different parameter errors.

For automotive applications, as mentioned earlier, the common remedies for avoiding parameter variation effects are based on look-up tables. However, these tables cannot perfectly cover the whole operating region without using a tremendous number of tables. In this regard, it is assumed that a parameter deviation in the amount of $\pm 20 \%$ inductance and $\pm 50 \%$ stator resistance is inevitable in practice. Thus, the esitmation accuracy of the designed state-filter should be examined under these conditions.

Fig. 3 and 4 show an FRF plot of the d-axis estimator with the detuned d-axis inductance $( \pm 20 \%)$ and the stator resistance $( \pm 50 \%)$, respectively. The state-filter bandwidth was set as $2000 \mathrm{rad} / \mathrm{s}$. Despite the inductance error condition, as shown in Fig. 3, the zero-phase lag is achieved at up to approximately $1000 \mathrm{rad} / \mathrm{s}$. This implies that the proposed voltage disturbance state-filter can achieve estimation without lagging within half of the observer bandwidth. The magnitude is slightly increased after $500 \mathrm{rad} / \mathrm{s}$, which means that it gives an estimation error in magnitude in the transient state. The resistance error has nearly no impact on the estimation.

The same result is obtained for the case of the q-axis estimator which is shown in Fig. 5 and 6. From the analysis, the proposed estimator is insensitive to electrical parameter errors at high frequencies.

\section{B. Compensation Strategy for Parameter Variations}

Based on (3), the torque error $\Delta T_{e}$ resulting from motor parameter variations can be obtained as:

$$
\Delta T_{e}=\frac{3}{2} \frac{P}{2}\left(\Delta \lambda_{p m}+\left(\Delta L_{d}-\Delta L_{q}\right) i_{d s}^{r}\right) \cdot i_{q s}^{r} .
$$

From (8) and (9), it can be seen that the outputs of the disturbance estimator at high speeds are:

$$
\begin{aligned}
\Delta \hat{v}_{d \_} D & =-\omega_{r} \Delta \hat{L}_{q} i_{q s}^{r} \\
\Delta \hat{v}_{q \_} D & =\omega_{r}\left(\Delta \hat{L}_{d} i_{d s}^{r}+\Delta \hat{\lambda}_{p m}\right) .
\end{aligned}
$$

Then, combining (10) and (11), the estimated torque error $\Delta \hat{T}_{e}$ can be described as:

$$
\Delta \hat{T}_{e}=\frac{3}{2} \frac{P}{2}\left(\frac{i_{d s}^{r}}{\omega_{r}} \hat{v}_{d_{-} D}+\frac{i_{q s}^{r}}{\omega_{r}} \hat{v}_{q_{-} D}\right) .
$$

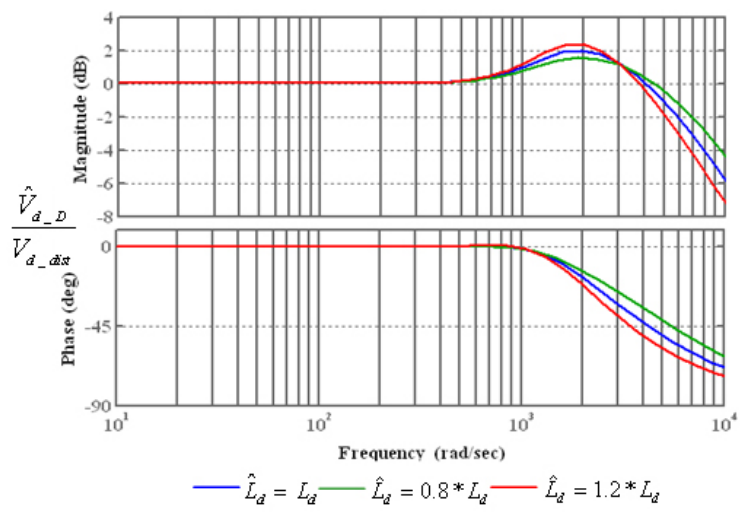

Fig. 3. FRF plot of d-axis disturbance estimator for detuned $\mathrm{L}_{d}$ by $\pm 20 \%$.

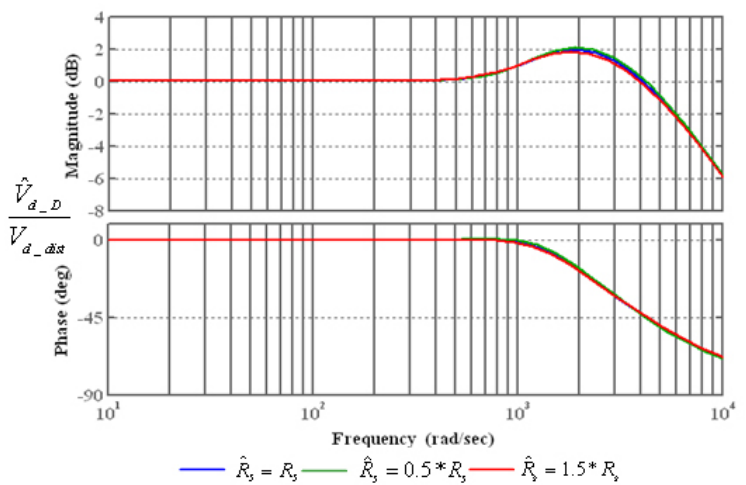

Fig. 4. FRF plot of d-axis disturbance estimator for detuned $\mathrm{R}_{s}$ by $\pm 50 \%$.

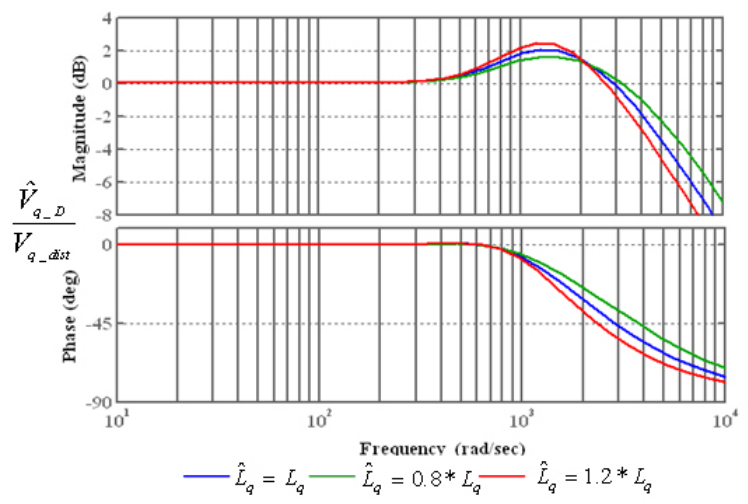

Fig. 5. FRF plot of $\mathrm{q}$-axis disturbance estimator for detuned $\mathrm{L}_{q}$ by $\pm 20 \%$.

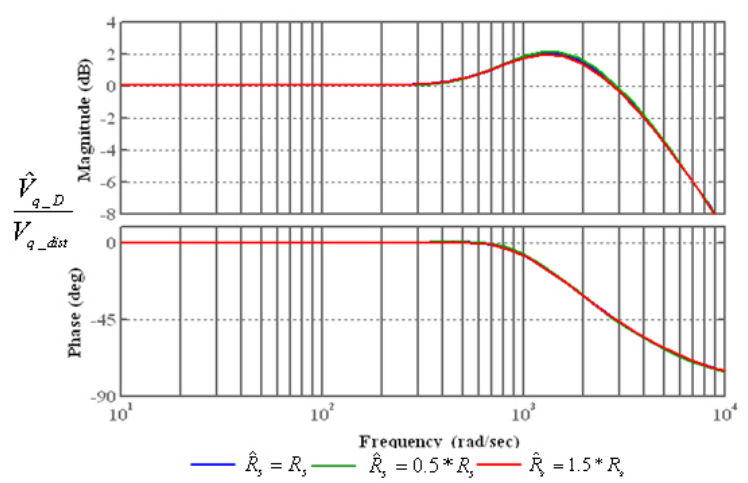

Fig. 6. FRF plot of q-axis disturbance estimator for detuned $\mathrm{R}_{s}$ by $\pm 50 \%$. 


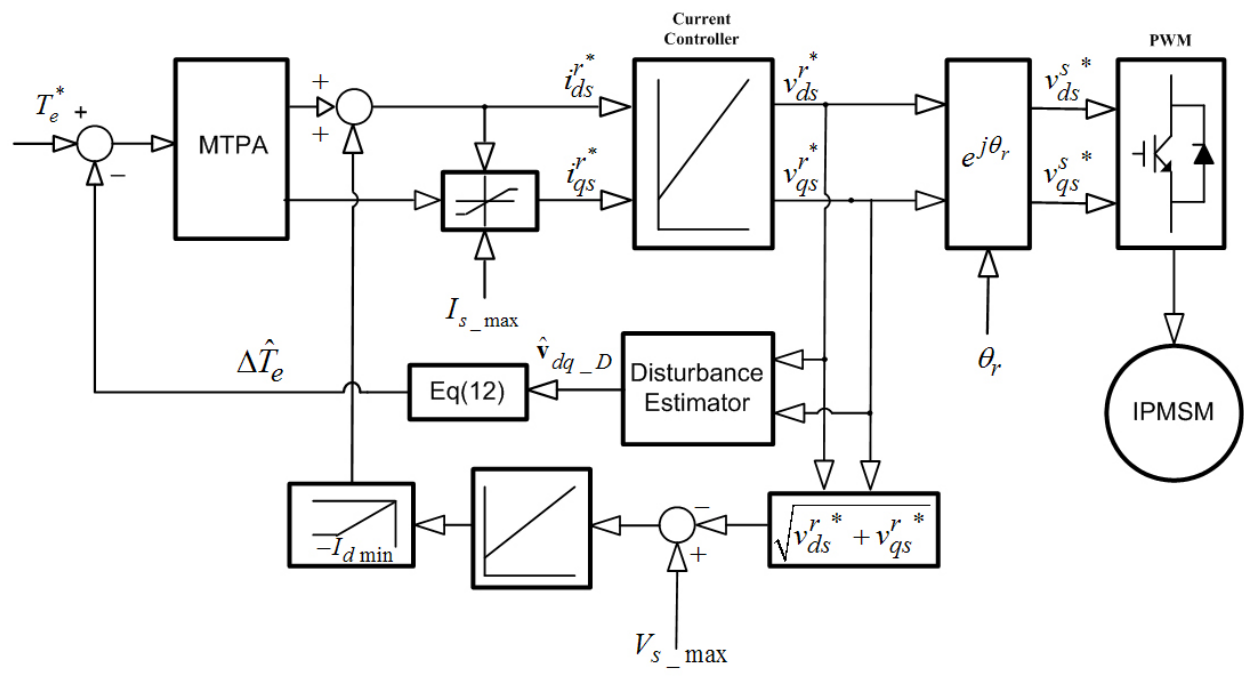

Fig. 7. Overall block diagram of the system.

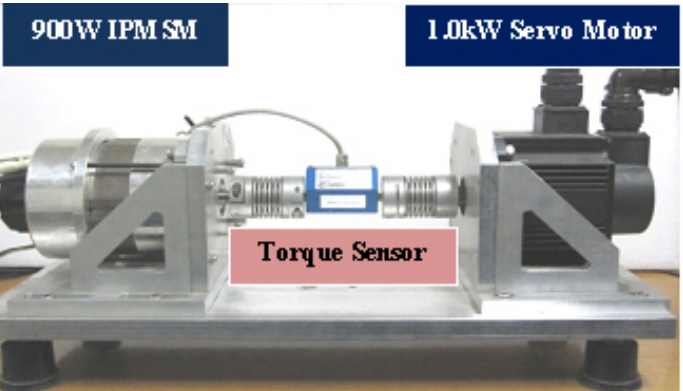

Fig. 8. Experimental setup.

Fig. 7 shows an overall control block diagram of the proposed scheme to compensate the parameter variation effects. Here, the estimated torque error in (12) is subtracted from the torque command in a feedforward manner, which automatically adjusts the effective torque command. Thus, this design can be effective for accurately estimating and compensating for disturbances over high speed operation ranges while reducing the computational complexity.

A fixed MTPA curve was implemented to utilize both the electromagnetic and the reluctance torque available in the IPMSM. The voltage feedback flux weakening control scheme is applied above the base speed [11].

\section{EXPERIMENTAL RESUlts}

The proposed algorithm was implemented on a $900 \mathrm{~W}$ IPMSM, as described in Table I, and coupled to a $1.0 \mathrm{~kW}$ servo motor as shown Fig. 8. An encoder of 2500 pulsesper-revolution was mounted at one end of the test motor to measure the actual position. A precise torque sensor with $\pm 0.25 \%$ accuracy was installed between the IPMSM and the servo motor to measure the actual generated torque. The torque sensor specifications are listed in Table II.

The PWM inverter consists of IGBT modules and two phase currents are sampled with a rate of $50 \mu \mathrm{s}$. The dc-link voltage was set to $100 \mathrm{~V}$ and the coupled servo drive was operated with a $1300 \mathrm{r} / \mathrm{min}$ speed command while a torque command (a)

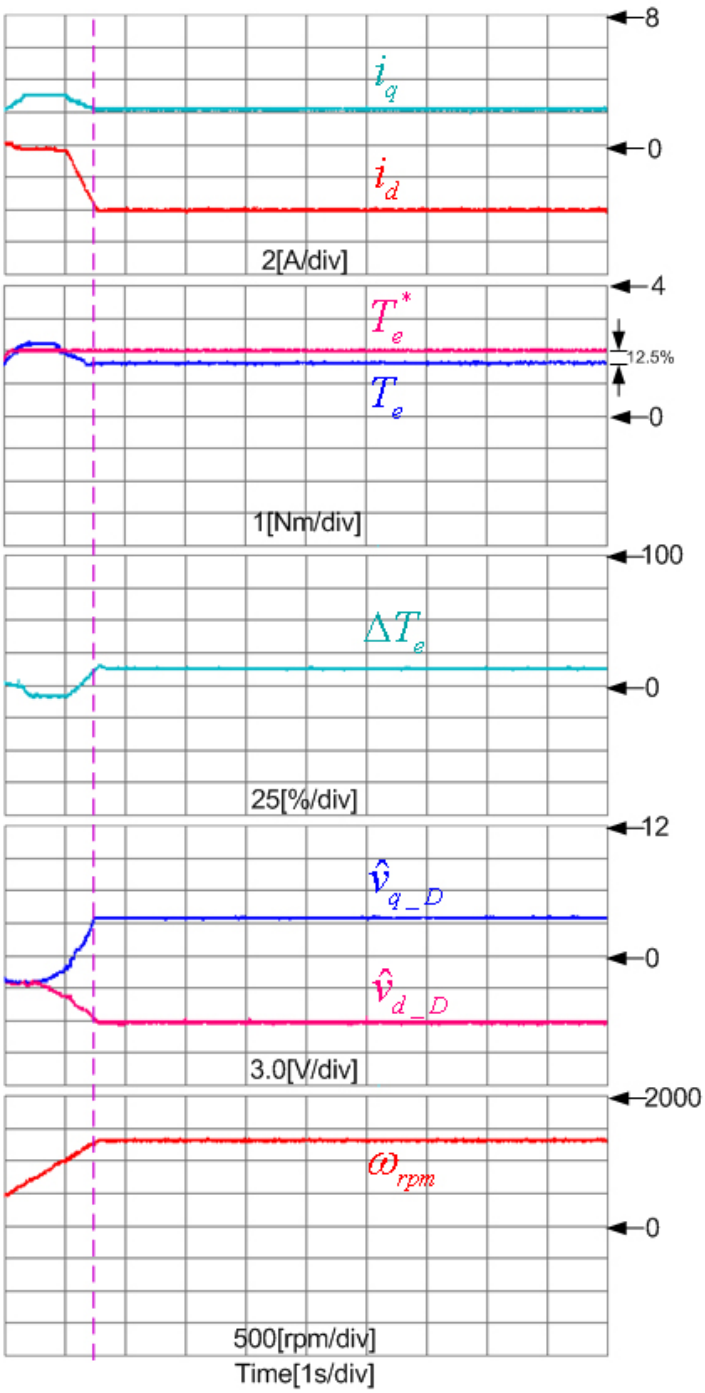

Fig. 9. Torque control performance without disturbance voltage compensation. (a) d and q axis current (b) Reference torque and measured torque. (c) Torque error. (d) Estimated disturbance voltage (e) Motor speed. 
TABLE I

RATINGS AND KNOWN PARAMETERS OF 900W IPMSM

\begin{tabular}{|l|l|l|}
\hline Ratings and Parameters & Value & Unit \\
\hline Rated torque & 2.9 & $\mathrm{Nm}$ \\
\hline Number of poles & 8 & \\
\hline$R_{s}$ & 1.82 & $\Omega$ \\
\hline$L_{d}$ & 8.5 & $\mathrm{mH}$ \\
\hline$L_{q}$ & 20.2 & $\mathrm{mH}$ \\
\hline$\lambda_{p m}$ & 0.115 & $\mathrm{~Wb}$ \\
\hline
\end{tabular}

TABLE II

SPECIFICATIONS OF TORQUE SENSOR

\begin{tabular}{|l|l|l|}
\hline Parameters & Value & Unit \\
\hline Supply Voltage & $11-16$ & $\mathrm{~V}_{\mathrm{DC}}$ \\
\hline Output Range & 2.0 & $\mathrm{Nm}$ \\
\hline Output Voltage & \pm 5 & $\mathrm{~V}$ \\
\hline Tolerances & \pm 0.1 & $\%$ \\
\hline
\end{tabular}

was applied to the IPMSM. At this speed, the IPMSM operates in the flux weakening region.

For the operation of the test motor, the MTPA control scheme was used below the base speed and the voltage feedback flux weakening control method was applied above the base speed. The online disturbance observer is performed every $50 \mu$ s and the state-filter bandwidth is set as $500 \mathrm{rad} / \mathrm{s}$.

Fig. 9 shows the torque control performance of the IPMSM without disturbance voltage compensation. In order to test the effect of parameter variations on the torque control without disturbance compensation, all the parameters were intentionally changed to $+20 \%$ of their nominal value. The tests were performed for a $2 \mathrm{Nm}$ torque command in the test motor. In this test, the steady-state torque error reaches to almost $0.25 \mathrm{Nm}$, i.e. $12.5 \%$ of the rated torque as shown in Fig. 9(b) and (c). Fig. 9(d) is shown to monitor the estimated voltage disturbance under the given conditions.

The same experiment was repeated using the disturbance compensation in the testing system. Here, the estimated disturbance voltage was delivered from the controller to compensate the parameter variation effects. The torque error was nearly reduced to zero (less than $\pm 2 \%$ ) as shown in Fig. 10(b). This control performance satisfies the $\pm 5 \%$ torque regulation limit in automotive applications. By employing the proposed algorithm, torque accuracy can be achieved within the regulation limit of automotive applications in the flux weakening operation ranges.

To examine the dynamic estimation performance of the proposed state-filter, $L_{d}$ was intentionally varied stepwise $+20 \%$ from its nominal value under a $1300 \mathrm{r} / \mathrm{min}$ speed command as shown in Fig. 11. In Fig. 11(b), it can be seen that the magnitude and the phase error in the controlled torque is rarely found.

Using the proposed algorithm, torque accuracy can be achieved within the $\pm 5 \%$ regulation limit of automotive applications in practical operating conditions.

The proposed state-filter has a simple structure and shows a fast estimation performance, without adding extra multidimensional look-up tables, when compared to existing strategies [2-5, 8-9]. It also identifies the variations of the IPMSM parameters due to magnetic saturation and temperature with minimal tuning efforts. (a)

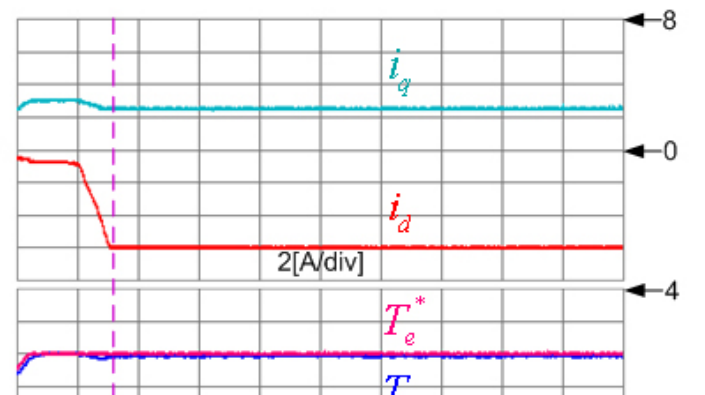

(b)

(c)

(d)

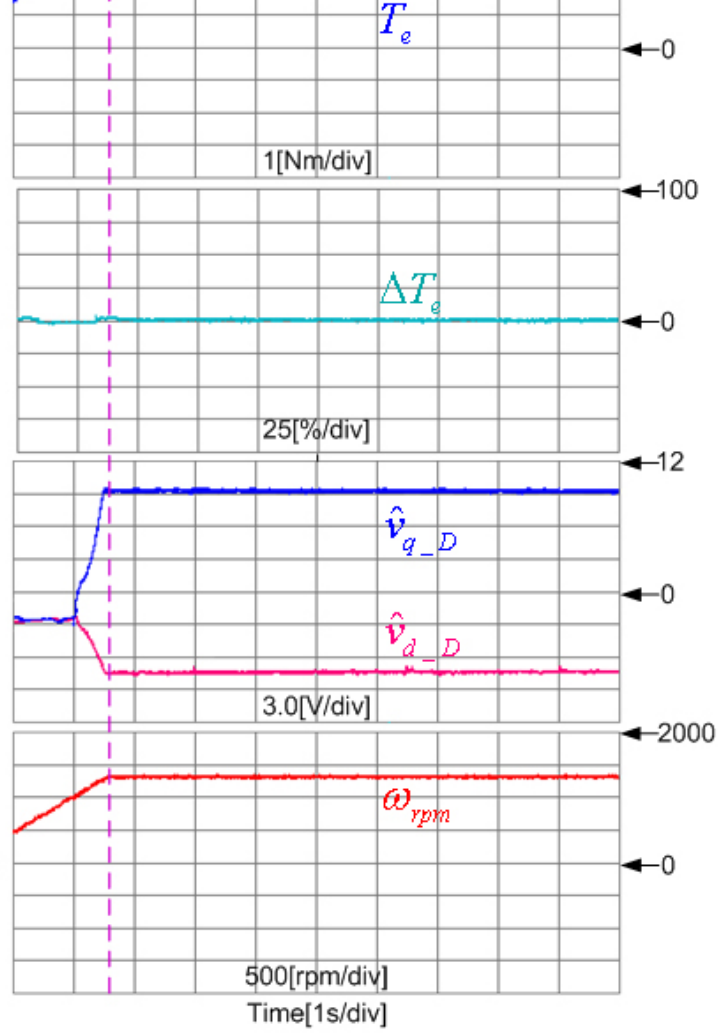

Fig. 10. Torque control performance with disturbance voltage compensation. (a) d and q axis current. (b) Reference torque and measured torque. (c) Torque error. (d) Estimated disturbance voltage. (e) Motor speed.

\section{CONCLusions}

Online voltage disturbance observers have been designed to compensate for the parameter dependency of precise torquecontrolled IPMSMs over a high speed range. By utilizing the FRF approach, the estimation accuracy and the disturbance rejection properties are analyzed. From the experimental results, it is concluded that the adoption of the proposed state-filter makes it possible to achieve accurate torque control in the presence of high saturation and temperature variations. Although the analysis presented in this paper is based on IPMSMs, the design concepts and conclusions can also be applied to nonsalient electric machines such as surface-mounted permanent magnet synchronous machines and induction machines.

\section{ACKNOWLEDGMENT}

This work was supported by a National Research Foundation of Korea (NRF) grant funded by the Korea government (MEST) (2010-0029428). 
(a)

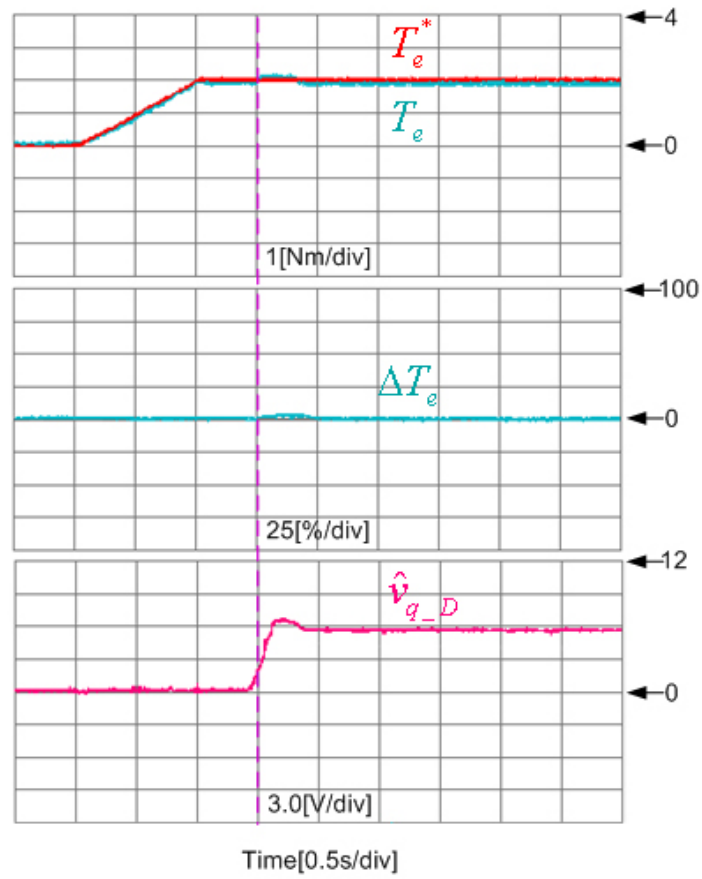

Fig. 11. Dynamic estimation performance of estimator changing $L_{d}$ by $20 \%$. (a) Reference torque and measured torque. (b) Torque error. (c) Estimated q-axis disturbance voltage.

\section{REFERENCES}

[1] S. R. Macminn and T. M. Jahns, "Control techniques for improved highspeed performance of interior PM synchronous motor drives," IEEE Trans. Ind. Appl., Vol. 27, No. 5, pp. 272-280, Sep./Oct. 1991.

[2] Y. S. Kim and S. K. Sul, "Torque control strategy of an IPMSM considering the flux variation of the permanent magnet," in Proc. IEEE IAS Anпи. Meeting, pp. 1301-1307, 2007.

[3] S. Morimoto, M. Sanada, and Y. Takeda, "Effects and compensation of magnetic saturation in flux-weakening controlled permanent magnet synchronous motor drives," IEEE Trans. Ind. Appl., Vol. 30, No. 6, pp. 1632-1637, Nov./Dec. 1994.

[4] L. Zhong, M. F. Rahman, W. Y. Hu, and K. W. Lim, "A direct torque controlled interior permanent magnet synchronous motor drive incorporating field weakening," IEEE Trans. Ind. Appl., Vol. 34, No. 6, pp. 1246-1253, Nov./Dec. 1998.
[5] B. Cheng and T. R. Tesch, "Torque feedforward control technique for permanent-magnet synchronous motors," IEEE Trans. Ind. Electron., Vol. 57, No. 3, pp. 969-974, Mar. 2010.

[6] Y. Jeong, S.K. Sul, S. Hiti, and K. M. Rahman, "Online minimumcopper-loss control of an interior permanent-magnet synchronous machine for automotive applications," IEEE Trans. Ind. Appl., Vol. 42, No. 5, pp. 1222-1229, Sep./Oct. 2006.

[7] A. Consoli, G. Scarcella, G. Scelba, and A. Testa, "Steady-state and transient operation of IPMSMs under maximum-torque-per-ampere control," IEEE Trans. Ind. Appl., Vol. 46, No. 1, pp. 121-129, Jan./Feb. 2010.

[8] H. Kim and R. D. Lorenz, "Improved current regulators for IPM machine drives using on-line parameter estimation," in Conf. Rec. IEEE-IAS, pp. 86-91, Oct. 2002.

[9] Y. Jeong and S. K. Sul, "Adaptive flux observer with on-line inductance estimation of an IPMSM considering magnetic saturation," in Conf. Rec. IEEE-PESC, pp.2467-2473, Jun. 2005.

[10] H. B. Kim, M. C. Hark and R. D. Lorenz, "Sensorless control of interior permanent magnet machine drives with zero-phase lag position estimation," IEEE Trans. Ind. Appl., Vol. 39, No. 6, pp. 1726-1733, Nov./Dec. 2003.

[11] T. S. Kwon and S. K. Sul, "Novel antiwindup of a current regulator of a surface-mounted permanent-magnet motor for flux-weakening control," IEEE Trans. Ind. Appl., Vol. 42, No. 5, pp. 1293-1300, Sep./Oct. 2006.

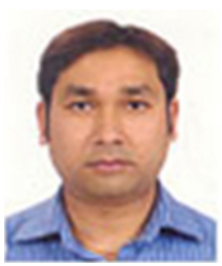

Rajendra L. Shrestha received his B.S. in Electrical Engineering from Tribhuvan University, Nepal, in 1999 and his M.S. in Electrical Engineering from Yeungnam University, Korea, in 2011. He is currently a Plant Manager for the Chilime HydroPower Company, Rasuwa, Nepal. His research interests include high-performance ac motor drives and control systems.

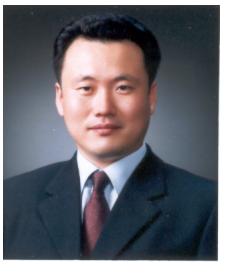

Jul-Ki Seok received his B.S., M.S., and Ph.D. from Seoul National University, Seoul, Korea, in 1992, 1994, and 1998, respectively, all in Electrical Engineering. From 1998 to 2001, he was a Senior Engineer with the Production Engineering Center, Samsung Electronics, Suwon, Korea. Since 2001, he has been a member of the faculty of the School of Electrical Engineering, Yeungnam University, Kyungsan, Korea, where he is currently an Associate Professor. His specific research interests include high performance electrical machine drives, sensorless control of ac machines, and nonlinear system identification related to the power electronics field. Dr. Seok is currently a member of the Editorial Board of the IET Transactions on Electric Power Applications. He is also serving as the current Vice Chair of the IEEE IAS-Industrial Drive Committee (IDC) Paper Award Department. 